\title{
Noticias digitales, comunidades virtuales y crisis institucional
}

\author{
Lila Luchessi \\ Universidad Nacional de Río Negro, Argentina \\ Universidad de Buenos Aires, Argentina \\ lluchessi@unrn.edu.ar
}

Recibido: 13/3/2018 / Aceptado: 4/4/2018

doi: 10.26439/contratexto2018.n029.1815

\begin{abstract}
Resumen. La producción informativa en contextos digitales genera flujos informacionales constantes. En este marco, la necesidad de actualización y continuidad provoca cambios productivos, pero también culturales, tanto en las organizaciones como en la sociedad. La acción de los usuarios establece un desplazamiento de los productores a otro plano: por la problemática financiera y los hábitos comunicacionales, la tradicional asimetría que regía la actividad informativa comenzó a equilibrarse con las demandas de quienes participan del proceso informacional. El objetivo de este trabajo es dar cuenta de las demandas informacionales de los usuarios, sus implicancias en las concepciones institucionalizadas de producción de información y el impacto de la descalificación de las voces autorizadas en la información cotidiana y la institucionalidad. Para abordarlo, se estableció un diseño exploratorio, sustentado en métodos cualitativos para acceder a informantes clave, tanto de la industria periodística como de las comunicaciones institucionales y los usuarios relevantes dentro de la red. Si bien los hallazgos no son aún estables, se cree central estipular que se encontraron constantes en relación con los flujos temáticos, las acciones productivas y las presiones comunitarias para la circulación de la información.
\end{abstract}

Palabras clave: periodismo digital / social media / comunidades de intereses / instituciones / flujo informacional 


\section{Digital News, Virtual Communities and Institutional Crisis}

ABSTRACT. News production within digital contexts generates a constant information flow. In this setting, the need for continuity and updating brings about productive and cultural changes, both in the news organizations and in society itself. The actions of users displace the producers from their original role. Given to financial problems and a shift in communication habits, the traditional asymmetry which ruled the news activity started to be balanced by the demands of those participating in the informational process. This work aims to address the informational demands of users, the implications of such demands in the institutionalized conceptions of news production, and the impact of the discredit of authorized voices on everyday news and institutionality. To deal with this subject, an exploratory design based on qualitative methods has been established aiming at having access to key informants, both in the news industry and the institutional communication system, and to relevant users within the web. Although findings have not shown a stable pattern yet, it is essential to stipulate that constants were found in relation to thematic flows, productive actions and pressures of the community for the circulation of news.

Keywords: digital journalism / social media / communities of interests / institutions / information flow 


\section{Introducción}

L

a inclusión de herramientas digitales en la producción informativa data de los años ochenta (Canavilhas, 2009, p. 51). En el comienzo, hizo posible editar textos e imágenes y simplificó la tarea periodística. Este cambio en los tiempos productivos también aceleró los ritmos de construcción de la información y las apropiaciones que los consumidores hacen de ella.

En los albores del siglo xxI, la brecha entre los intereses informacionales de los productores y sus audiencias se sostuvo en que el nuevo contexto tecnológico derivó en la reducción de la asimetría de saberes, intereses y fuentes informativas. Sin embargo, y de modo inversamente proporcional, la diferencia de intereses temáticos, de coberturas y preferencia de información registró distancias más grandes (Boczkowski y Michelstein, 2013).

La masificación del consumo de telefonía celular y la baja en los costos de conectividad a internet hizo que los usuarios aumentaran rápidamente. Según datos del Ente Nacional de Comunicaciones de Argentina (Enacom, 2017), la penetración de telefonía celular por cada 100 habitantes fue de 141,05\% en el tercer trimestre del 2017. Esta tendencia se mantiene desde el 2008 cuando este indicador trepó por encima del $100 \%$ (Cabot, 2015). El abaratamiento de los dispositivos digitales redundó en un crecimiento de los usuarios de telefonía móvil y una ampliación de la oferta de sus usos, que condujo a que se abrieran nuevas oportunidades de negocios para los medios y la prensa.

En un principio, las empresas concibieron el negocio con las mismas lógicas que habían aplicado hasta ese momento. Sin embargo, con el crecimiento sostenido de los productos digitales, la inclusión masiva de los consumidores y las apropiaciones de los lenguajes que estos comenzaron a hacer, el mercado se fue ampliando hasta generar un nuevo modo de producir y publicar información en la web. Los reenvíos a los medios tradicionales, sus rutinas productivas y los modos de consumo establecieron interacciones que, como plantea McLuhan (1964), dejan a la vista las remisiones a los otros medios. En este sentido, se estipula la construcción de un nuevo lenguaje a partir de la interacción con los precedentes.

De estas interacciones surge una reconfiguración de la narrativa y de los flujos de información. Sin embargo, recién en el primer lustro del nuevo siglo, con la irrupción de las plataformas digitales en red y la masificación del consumo de dispositivos móviles, aparecen amplificadas las voces de la sociedad. Entonces, los hábitos de consumo - devenidos de los usos de los nuevos clientes- y la innovación tecnológica en relación con los dispositivos móviles llevan a que una primera perspectiva de presentar la información, tal vez conservadora, tuviese que cambiar.

En este contexto, los medios periodísticos experimentan un triple problema. Por un lado, la incorporación de las herramientas digitales como insumo 
para la construcción de las noticias. Por otro, el uso de las mismas herramientas como plataforma para la publicación e interacción con sus públicos. Finalmente, la acción directa de la audiencia sobre el contenido que se llega a publicar.

Con respecto a este último punto, dado que las audiencias no son -ni tienen por qué ser- expertas en producción informativa, los criterios tradicionales de construcción noticiosa se subvierten y generan incomodidades en los productores de información. Entonces, los profesionales de la prensa se descolocan y no encuentran, aún, formas adecuadas de responder a las demandas de la audiencia sin perder lo que consideran el deber ser de la profesión (Luchessi, 2016).

La interactividad, inherente a las plataformas digitales, perturba los lenguajes y estructuras de la comunicación periodística. Pero, fundamentalmente, cambia las relaciones entre los productores y los usuarios informacionales conectados a la red. En este sentido, Jenkins (2008) advierte que la convergencia es un fenómeno cultural, "ya que anima a los consumidores a buscar nueva información y a establecer conexiones entre contenidos mediáticos dispersos" (p. 15). A partir de este modo segmentado, surgido de formas incidentales de consumo (Boczkowski, Michelstein y Matassi, 2016), las fidelidades se pierden y los contextos se erosionan. A pesar de tener presencia en las distintas plataformas, las empresas informativas se presentan como pizarras de anuncios, canales de difusión, correas de transmisión que, casi en ningún caso, permiten interacciones con los demás actores del sistema informativo. Piqué (2008) explica en la introducción del libro Periodismo integrado:

Es necesario revisar el proceso de toma de decisiones editoriales y de edición, promover nuevos perfiles profesionales, ajustar las funciones de reporteros y editores, mejorar la comunicación entre secciones, renovar la planificación de coberturas, elaborar nuevos formatos informativos, sumar más contenidos noticiosos al menú. (p. 8)

Sin embargo, el logro de estos objetivos no es viable si las empresas periodísticas no se disponen a invertir en sus redacciones.

Como fenómeno cultural, la convergencia acarrea problemas asociados a la identidad que, para los periodistas, implican parámetros profesionales $\mathrm{y}$, para los usuarios, posicionamientos políticos, estéticos y sociales. Acerca de las relaciones que se establecen entre unos y otros, diremos que la cultura corporativa de los periodistas los conduce a concebirlas como interacciones verticales. En cambio, los usuarios, devenidos en miembros de comunidades de interés, las realizan entre distintos integrantes de estos grupos. Las interacciones intercomunitarias son entre pares y, de ese modo, horizontales (Luchessi, 2018). A medida que los consumidores de noticias se vuelcan a los formatos digitales, la interacción con sus pares se vuelve frecuente. La discusión, colaboración, conversación y participación fluye de modo horizontal entre ellos. A pesar de esto, los casos de análisis tomados para este estudio no 
dan cuenta de respuestas, correcciones, agradecimientos o polémicas por parte de las instituciones periodísticas o los autores de sus notas, que se mantienen distantes de sus públicos.

Desde el surgimiento de Facebook en el 2004 y de Twitter en el 2006, el crecimiento de usuarios es exponencial. Según datos del Reuters Institute Digital News Report (Newman, 2017, p. 12), Facebook lidera el uso de plataformas de redes sociales. El $70 \%$ de los usuarios de herramientas digitales tienen cuenta en esa red, el $61 \%$ en YouTube, el $24 \%$ en Instagram, el $20 \%$ en Twitter y el $14 \%$ en LinkedIn. Respecto de las aplicaciones de mensajería, el reporte indica que WhatsApp lidera los consumos con una penetración del $40 \%$ del segmento. Facebook Messenger retiene el $36 \%$, Snapchat el $9 \%$, Viber el $7 \%$ y WeChat el $4 \%$.

Ya inmersos en los datos de Argentina, se informa un $79 \%$ de penetración de internet. Este porcentaje, cruzado con la penetración del uso de telefonía móvil, diluye la discusión sobre el acceso y la participación que monopolizó los debates en los años noventa. Además, el informe revela que tanto las redes sociales como las aplicaciones de mensajería se utilizan como vehículo de información.

Tabla 1. Ranking en el uso informativo y general de las redes sociales

\begin{tabular}{llcc}
\hline Ranking & \multicolumn{1}{c}{ Marca } & $\begin{array}{c}\text { Uso informativo } \\
\%\end{array}$ & $\begin{array}{c}\text { Uso general } \\
\%\end{array}$ \\
\hline 1 & Facebook & 65 & 83 \\
2 & WhatsApp & 33 & 76 \\
3 & YouTube & 28 & 75 \\
4 & Twitter & 19 & 32 \\
5 & Facebook & 10 & 42 \\
\hline
\end{tabular}

Fuente: Datos del Digital News Report para Argentina (Rost, 2017, p. 105)

Sin embargo, esos datos de penetración no redundan en una mayor calidad informativa (Luchessi, 2013). Es solo con información sobre los comportamientos de la audiencia que los medios pueden tomar decisiones acertadas:

Los datos que arrojan la forma de navegación, el tiempo estimado de perma- nencia en el sitio, las notas más leídas, las más comentadas o las más compartidas, de dónde llega el tráfico al sitio (redes sociales, Google, navegación directa) son herramientas muy valiosas para tomar decisiones editoriales. (Pozzo, 2015, p. 38)

Aun así, la cultura de los profesionales de la información está lejos de 
manejar estos datos. Además, no hay una plena conciencia de que, "condicionada ergonómicamente por el dispositivo, la producción y la lectura de contenidos está sujeta a textos de pocas líneas, a la brevedad de los videos de pocos segundos" (Igarza, 2009, p. 127).

En algunos casos, los medios periodísticos interpelan a sus audiencias para pedirles material informativo al que ellos no tienen acceso. Canales de YouTube, páginas en Facebook, Twitter e Instagram se combinan con cuentas en WhatsApp y Snapchat. A través de ellas reciben denuncias, videos, datos y otros insumos para generar contenidos. No obstante, son muy pocos los registros de agradecimientos, citas de fuentes o respuesta cuando es la audiencia la que usa esos canales para demandar.

Así las cosas, los usuarios tienden a salirse de lo previsible para comenzar a elaborar información que rompe la lógica de la construcción informativa tradicional. A medida que las redes se vuelven más y más masivas, los temas y preocupaciones de los usuarios circulan sin la necesidad de la mediación periodística. Inmersos en la nueva realidad, los profesionales corren detrás de flujos de dos tipos: informativos y de consumo (Pozzo, 2015).

Asimismo, con herramientas para la segmentación y la identificación de públicos basadas en métricas que permiten observar la conformación de nodos dentro de ellas, los anunciantes también pueden acceder a sus consumidores sin usar superficies mediáticas.
Este hecho acarrea dos problemas para las empresas periodísticas. Por un lado, el financiamiento de los contenidos, ya que la inversión publicitaria se reduce. Ante una torta que - en el mejor de los casosse mantiene estable, el crecimiento de la oferta de contenidos tradicionales y digitales hace que el mercado de las noticias comience a trastabillar. Por otro, un cambio sustancial en la idea de información (Aguado, 2013).

Este fenómeno, que atraviesa el mercado periodístico global, se profundiza por las diferencias ideológicas que marcan nuevos nichos y segmentos dentro de la opinión pública. Definido por el periodista Jorge Lanata como "grieta", el antagonismo que surge en los posicionamientos políticos, sociales e informacionales transforma a las agendas en superficies paralelas, en las que todos son mayoría y parecen tener razón.

Las secciones tradicionales ya no dan cuenta de las preocupaciones, preferencias y costumbres actuales. En algunos casos, pueden registrarse adecuaciones para sostener los pactos de consumo con el público. Pese a ello, la baja en los índices de credibilidad (Amado, 2016b) y la posibilidad de publicar sin mediación de la prensa hacen que muchos cibernautas ya no requieran de su participación, reagrupándose en comunidades que confirman sus prejuicios. Son diversos los estudios sobre la conformación de comunidades en las redes, como el de Calvo (2015) que analizó los comportamientos que se realizaron en Twitter en relación con la muerte del fiscal Alberto Nisman. 


\section{Marco teórico}

Para el desarrollo de la investigación, se trabajó con categorías que surgen o se adecúan a la incorporación de tecnologías digitales. De este modo, las ideas de newsmaking y gatekeeping subyacen en el artículo, aunque se tenga en cuenta que la actividad de los usuarios puede impactar tanto en la práctica periodística como en la construcción identitaria en relación con la profesión.

Jenkins (2008) asegura que el concepto de los marcos convergentes se define así:

[...] el flujo de contenido a través de múltiples plataformas mediáticas, la cooperación entre múltiples industrias mediáticas y el comportamiento migratorio de las audiencias mediáticas, dispuestas a ir casi a cualquier parte en busca del tipo deseado de experiencias de entretenimiento. (p. 14)

Esto provoca que, además de los flujos informativos que llegan por oleadas a cada uno de los periodistas, se establezcan pulsos: continuos, pero a la vez dinámicos, para la satisfacción del consumidor. "El pulso habla de continuidad y de actualización, de ritmo y de particularidad" (Pozzo, 2015, p. 65). Entonces, los flujos y los pulsos deben pensarse de forma relacional para comprender una comunicación que se retroalimenta instantáneamente y por fuera de la periodicidad.

Las organizaciones sociales tienden a conformarse a través de redes relacionales (Barnes, 1954; Bott, 1957). Al respecto, tanto la antropología como la sociología han dado cuenta de la importancia del estudio de las relaciones que conforman las estructuras sociales (Wasserman y Faust, 1994) y los vínculos que se establecen dentro de ellas. Las estructuras que indican la conformación de redes sociales, viables para analizar tanto las comunidades de usuarios como las identidades profesionales de los periodismos contemporáneos, también dan cuenta de los nodos de contenidos $\mathrm{y}$ ponen en jaque la idea de agenda (McCombs, 2004).

Si se analizan las tramas relacionales en las que las sociedades interactúan, la amplificación de las voces a través de las plataformas tiene un doble circuito. Por un lado, el uso de las redes se vuelve individual y, a veces, aislado. Por otro, la interacción genera nodos, liderazgos y matrices que no hacen otra cosa que reproducir en las plataformas virtuales lo que sucede en las comunidades reales, independientemente de las tecnologías predominantes. En este sentido, creemos con Castells que "la sociedad modela a internet y no al contrario. Hay que cambiar la política para cambiar internet $\mathrm{y}$, entonces, el uso político de internet puede revertir en un cambio de la política en sí misma" (citado por Gómez, Ortiz y Concepción, 2011).

Desde este punto de vista, si la asimetría monopolizada por los medios se desdibuja, las brechas de intereses entre ellos y sus usuarios se amplían (Boczkowski y Michelstein, 2013). Frente a comunidades desafiantes, los medios establecen formas de construcción negociadas para no perder views, flujos, pulsos 
y circulación. Así, el poder de los medios para fijar la agenda (McCombs, 2004) se difumina en una doble tensión: por un lado, por las demandas de las comunidades que establecen tópicos, tendencias temáticas y lenguajes desacartonados y breves; por otro, los problemas de financiamiento que se suscitan cuando los anunciantes se retiran de la pauta publicitaria para comunicarse sin intermediación con sus clientes.

Las formas relacionales más comunes dentro de lo que llamamos interacciones horizontales son binarias. Como plantea Calvo (2015), en los "barrios de internet", que agrupan comunidades homogéneas en términos filosóficos y políticos, se sostienen relaciones en las que los buenos y los malos cambian de signo, de acuerdo con la integración de cada comunidad. No hay allí lugar para procesos tradicionales, contradicciones ni dudas a la hora de construir noticias, jerarquizarlas y editarlas. La demanda pide - con formas poco elegantes - relatos verosímiles para cada comunidad. Es en estas superficies donde se dirime la disputa por quién es efectivamente mayoría. Y, si no se logra, es a fuerza de insulto, descalificación o bloqueo como se cree tener la razón.

Por diversas cuestiones, hay contenidos que no son mediatizados a través de las instituciones periodísticas. En algunos casos, lo que opera es la tradicional forma de aplicación de los criterios de noticiabilidad. En otros, lo que rige es lisa y llanamente la censura. Finalmente, existen otros que no son mediatizados porque no cumplen con ninguna adecuación respecto del concepto de noticia, entendida como "la construcción periodística de un acontecimiento cuya novedad, imprevisibilidad y efectos futuros sobre la sociedad lo ubican públicamente para su reconocimiento" (Martini, 2000, p. 33).

Sin embargo, el denominador común de estos contenidos - que van desde las redes a la prensa tradicional-es la gran cantidad de clics, views y shares. Es decir, los rastros del flujo y el pulso que circula por la web, y que ponen de manifiesto los rasgos de las nuevas concepciones de la vida, la cotidianidad y la mirada sobre las instituciones. El concepto de spreadable media (Jenkins, Ford y Green, 2013) resulta operacional para comprender la complejidad de este fenómeno. La acción y participación de los usuarios excede la idea de contagio y refuerza la de una acción concreta y voluntaria para el fomento de la circulación.

Según plantea Scolari (2013), las negociaciones y tensiones "pueden terminar en acuerdos temporales de cooperación". En América Latina, los antecedentes de estas disputas entre industrias culturales y cultura colaborativa pueden hallarse en las obras de Jesús MartínBarbero (1987), Aníbal Ford (1994) y Néstor García Canclini (1990), así como en la obra de Scolari (2008), donde se analizan las negociaciones, préstamos y tensiones entre la lógica de la industria tradicional y la de los miembros de las comunidades, sean ellos integrantes de grupos étnicos o usuarios participativos en las redes digitales. Los análisis sobre la conformación de comunidades, grupos de opinión, liderazgos virtuales 
y rupturas estructurales frente a las convenciones establecidas antes del auge de las plataformas digitales tienden a repetir hallazgos que se relacionan más con prácticas sociales y culturales instituidas antes de la existencia de plataformas y aplicaciones específicas. Sin embargo, la característica más clara de sus irrupciones es la velocidad con la que pueden realizarse las interacciones. Regidos por la contemporanización imperante, los usuarios interactúan instantáneamente acerca de puntos en debate, posicionamientos ideológicos y acciones en común. Lo novedoso, tal vez, es que las voces opuestas son obturadas y se remite a ellas para descalificarlas.

Si se comparan los resultados de las investigaciones sobre las interacciones en las redes digitales con las que se producían antes de la existencia de las plataformas, se puede encontrar que los lazos relacionales y las conformaciones de nodos jerarquizados dentro de cada una de ellas se mantienen estables, respecto de lo que podía observarse en las comunidades establecidas en distintos territorios. El cambio, quizás, sea que la virtualidad exacerba la virulencia que, de darse personalmente, sobrepasaría el bloqueo para terminar en tragedia. Al respecto, Steven King sostiene: “Lo ideal sería coger todos estos elementos e introducirlos en nuestra forma de informar. Para ello, tanto la realidad aumentada como la virtual tienen unas posibilidades muy grandes, son potentes" (García, 2017). Y agrega que la gamificación podría dar resultado. Sin embargo, las empresas insisten con fórmulas tradicionales que, por el momento, no redundan en autofinanciación.

Por lo demás, concordamos con Jenkins (2008) en que la transmedialidad es necesariamente interactiva. Esta ruptura narrativa permite analizar un contexto informativo que deja de lado la unidireccionalidad producida por las empresas periodísticas para aportar a un palimpsesto digital, en el que los participantes dialogan, constituyen lazos, descentran las jerarquías institucionalizadas tradicionalmente para construir otras. Entonces, de esta mezcla desjerarquizada de tópicos que se yuxtaponen a alta velocidad surgen nuevas formas de socialización y relaciones con la información.

Al mismo tiempo, resulta de interés estudiar las relaciones que establecen los usuarios entre ellos. Si examinamos foros y redes de los medios, las intervenciones de la audiencia suelen ser conversacionales e interactivas, aunque esos intercambios se produzcan solo de manera horizontal. En la mayoría de los casos, los usuarios interpelan, provocan, desacreditan y cuestionan la autoridad del periodismo - en cuanto institución- para la fijación de las agendas y la explicación de los acontecimientos sociales.

Los índices de credibilidad de la prensa, en el tope de los rankings en la década de los noventa, decrecen año tras año (Amado, 2016b), a medida que la participación de la audiencia se masifica y construye un diálogo del que periodistas y empresas de medios deciden autoexcluirse. La vieja idea que los constituía 
en portadores de un saber desconocido para el resto se desmorona frente a las creencias que elaboran las comunidades portadoras de poca información, pero convencidas de la revelación de alguna verdad. Llegados a este punto, podemos hacer dos apreciaciones que contextualizan las prácticas periodísticas y las relaciones con los usuarios. En primera instancia, del análisis realizado sobre el contenido de publicaciones acerca de noticias de interés público surge un cuestionamiento a la institucionalidad del periodismo como actor central del proceso informativo, una caída de la credibilidad respecto de lo que publica y una mayor cohesión y credibilidad de las comunidades de las que se forma parte y a las que se considera fuentes confiables. Luego, si se estudian las manifestaciones en el espacio público y los reclamos que surgen de ellas, el cuestionamiento a la institucionalidad del sistema democrático, la jerarquía de quienes lo representan y la credibilidad de las dirigencias, pueden encontrarse correlaciones asociadas a un fortalecimiento de la participación comunitaria, con una construcción de liderazgos concebidos de forma reticular.

En relación con los estudios sobre periodismo, vemos que desde los tiempos de análisis de la prensa escrita, se empieza a pensar las rutinas de trabajo (Gans, 1979), las formas para la construcción de la información (Tuchman, 1978) y los modos de influencia en la opinión pública (Lippman, 1922; Habermas, 1981; Price, 1994).
Tradicionalmente, para indagar el proceso constructivo se establecen tres instancias: la selección de los temas, la jerarquización y la edición del contenido, que luego será publicado en medios de comunicación reconocidos socialmente por la audiencia (Martini, 2000). Este proceso, en el que el insumo informacional llega a la redacción para ser profesionalmente procesado y publicado, es el que se conoce como newsmaking.

Las noticias, entonces, se generan con la sistematización de aquellos acontecimientos que se organizan a partir de su planificación y con el seguimiento de las rupturas que los hechos provocan en la vida cotidiana, que alteran la rutina productiva de los periodistas y sus trabajos. Los criterios con los que se articulan las rupturas permiten gerenciar la producción informativa y ordenar la agenda periodística (McCombs, 2004) en torno a las disputas por el sentido que se establecen en la sociedad.

Desde este punto de vista, las tradicionales tensiones por la agenda requerían, al menos, de tres actores centrales: los políticos, los medios periodísticos y la sociedad. De esas disputas y negociaciones surgían los temas y los encuadres sobre los cuales la opinión pública debía informarse para posicionarse según sus pertenencias sociales, ideológicas, sectoriales, políticas y culturales. No obstante, con la aceleración productiva de todo el sistema social y la modificación perceptual del concepto de tiempo, los roles se descentran, las jerarquías dentro del sistema cambian y las interacciones del 
periodismo con sus fuentes informativas, de financiamiento y con la sociedad se empiezan a modificar.

En contextos capitalistas, la aceleración y la velocidad son necesarias para generar competencia y productividad (Gitlin, 2005, p. 102). Sin embargo, la velocidad que se imprime con la digitalización de las plataformas hace que cambie la valoración temporal completa. Si bien las técnicas productivas no resultan novedosas, la posibilidad concreta de sincronizar los tiempos del acontecimiento y de la publicación echa por tierra el concepto de periodicidad (Luchessi, 2013). Inmersos en un proceso al que denominamos de contemporanización, que establece una sincronía temporal entre el acontecimiento, su publicación y el consumo, se genera - a partir de las tecnologías digitales- la posibilidad de incorporar la idea de simultaneidad espacial. La concepción del aquí y ahora -permanente, descontextualizadaimpacta en las construcciones culturales, en la valoración de las producciones sociales y en los intereses informacionales de las comunidades en red.

A las modificaciones culturales que implica el consumo audiovisual domiciliario con la introducción y masificación de la televisión de pago - estudiadas por Landi (1992) - , hay que agregar ahora la posibilidad de interacción que se genera con la incorporación de plataformas digitales. Las audiencias a las que se refería Landi mantenían aún relaciones asimétricas con los productores de información. En tiempos de plataformas, los liderazgos y las reputaciones también se construyen por cantidades de seguidores, clics y omnipresencia digital. De allí que ignotos personajes, desconocidos por los medios y las comunidades no virtuales, pueden ser convocados por ellos mismos a partir de la popularidad de sus publicaciones. Los liderazgos, entonces, ya no dependen solamente de la capacidad de actuar socialmente y su repercusión informacional, sino, y sobre todo, de la habilidad para interpelar con rapidez a grandes grupos de la comunidad que se integra.

Para comprender estas modificaciones, es necesario tener en cuenta el acceso directo - y a través de tecnologías fácilmente disponibles - a los acontecimientos que se producen en territorios remotos, desconocidos y culturalmente extraños para la institución periodística. Este acceso de actores desconocidos en ámbitos institucionalizados rompe con la idea tradicional de distancia, expresada en millas o kilómetros, para permitir una sincronía espacial dentro de un tiempo que también es sincrónico. Así, personajes desconocidos por la gran prensa pueden irrumpir como voces relevantes para la sociedad.

En este marco, la periodicidad, la primicia y la actualidad pierden vigencia dentro de los valores noticia conocidos hasta el momento. La preponderancia de los productores, erosionada por la fuerte participación de los usuarios en las redes, se caracterizó por unos criterios de noticiabilidad estables. Pero, en un contexto en el que esa asimetría se resquebraja y los usuarios dejan sus pasividades, al tiempo que interactúan en las redes, los 
criterios cambian y las formas de producción también (Amado, 2016a).

Los cambios de hábitos en los consumidores y en las estrategias de marketing directo, llevadas adelante por los anunciantes y los actores que antes eran fuentes de información, ponen a las empresas periodísticas en verdaderos problemas. La asimetría, característica de la tradición informativa sustentada en el periodismo como mediador entre el poder y la sociedad, se ve rota por la posibilidad del contacto directo con fuentes y anunciantes de acuerdo con intereses muy específicos. La información directa y la evasión de intermediarios para el acceso al consumo representan una transformación en la mentalidad con la que se expresa la sociedad. Así, se observa que los usuarios de plataformas y aplicaciones informativas acceden a fuentes directas. En muchos casos, poseen información antes que los propios medios. Y, en algunos otros, resultan fuente o insumo para el sistema de información. Asimismo, políticos, líderes sociales, miembros del star system, junto con nuevos referentes - surgidos de las mismas redes - jaquean el concepto de primicia y dejan a los profesionales de los medios en una situación de retraso temporal en la cobertura de los acontecimientos, en relación con los actores que circulan por la red.

La instantaneidad se afianza como criterio de selección noticiosa para los usuarios. La avidez por conocer lo que sucede genera una ansiedad en el consumo, que atenta contra el proceso de newsmaking, es decir, las tareas conocidas para los periodistas y las formas de financiamiento necesarias para sostener el negocio de la información. En ese sentido, los tiempos de producción se acortan, con su consecuente impacto sobre la calidad de las noticias. Al mismo tiempo, la sociedad se sumerge en una idea de contemporaneidad constante, en la que los contextos políticos, culturales, económicos y sociales se pierden en la carrera por el tiempo que, para ser efectiva, debe tender a igualar el momento del acontecimiento con el de la publicación.

Una de las consecuencias más llamativas de este proceso es la del nacimiento de construcciones ahistóricas, donde todo remite al pasado reciente sin posibilidad de contextualización. Aun así, por las redes circulan viejas piezas informacionales que se actualizan por el interés cuantificado de los usuarios. En esos casos, los criterios, como la espectacularización, el entretenimiento o el posicionamiento ideológico preponderante dentro de una comunidad, hacen que muchos de sus integrantes se interesen por el contenido, aunque no revista correspondencia alguna con el presente del suceso. Por tanto, el tiempo ya no se construye de manera lineal (Sibilia, 2012), sino que se establece como el presente de la publicación.

La cobertura periodística, valorada en contextos tradicionales como forma profesional de gestionar y presentar la información, corre en desventaja con la publicación compulsiva de datos erróneos, incompletos o directamente falsos. Además, el volumen de contenidos que 
circula por la red mezcla información relevante con aquella que no lo es, con la privacidad y el entretenimiento.

Es en este escenario donde las audiencias suelen aglutinarse en comunidades que les son afines (Calvo, 2015). En ellas, se refuerzan sus prejuicios, creencias y posicionamientos. De este modo, la veracidad de la información no está cuestionada, sino la posición que los medios o los periodistas pueden manifestar sobre el tema que abordan.

Esta reconfiguración de la publicidad de los acontecimientos sociales, gerenciada directamente por los equipos de comunicación de las fuentes, opera en forma directa sobre las rutinas productivas de la información e, indirectamente, sobre quienes se exponen a sus contenidos. Transformados en reproductores de lo que ya todos saben, los periodistas dejan el lugar de la narración de los hechos para atrincherarse en sus escritorios, conectados a las redes y sin tiempo para una gestión profesional que les permita confirmar los datos y agregar información. Sin embargo, y a pesar del auge de las controversias acerca de las fake news, King cree que la clave está en la narración de buenas historias, adecuadas a las herramientas y dispositivos que permiten mezclar elementos surgidos en otros ámbitos.

El ejemplo más sencillo de entender es el de los videojuegos y la gamificación. Títulos como Halo venden millones y millones de copias en menos de un día. ¿Por qué? Tienen buenos personajes, buenos gráficos, una gran historia y una comunidad detrás que lo respalda. (García, 2017)
El desafío de construir buenas historias hace que algunos sitios resulten exitosos para comunidades ávidas de relatos con respaldo informativo. Sin embargo, la industria no apuesta por miedo al riesgo y las versiones digitales de los medios industriales se conforman con elaborar contenidos que se sustentan en las acciones de copiar y pegar.

El proceso de newsmaking, que comienza con la llegada de información a las redacciones, se ve modificado porque el acceso de los periodistas a esos datos suele coincidir con el acceso de la audiencia a los mismos. En este sentido, la diferencia entre unos y otros estaría dada por la jerarquización que suponen los tradicionales criterios de noticiabilidad.

En la medida en que la comunidad ya no se reconoce necesariamente en fronteras territoriales o mitos nacionales, en las redes, la identidad comunitaria se construye a través de consensos culturales vinculados con intereses, expresiones y consumos reticulares. Así, la importancia de los acontecimientos y su valoración como insumo informacional también se subvierte por la consagración de una brecha (Boczkowski y Michelstien, 2013) que deja al descubierto los intereses editoriales y personales de los periodistas, y sus consecuentes distanciamientos de los que elaboran sus usuarios. A pesar de esto, la tensión entre unos y otros suele desvanecerse cuando las acciones que salen de la web hacia el territorio construyen nuevos activismos que resultan de interés informativo para el periodismo tradicional. 


\section{Metodología}

Esta investigación se sustenta desde una perspectiva multimetodológica y transdisciplinaria. El trabajo es exploratorio y se apoya en entrevistas en profundidad. Los entrevistados fueron periodistas de medios industriales con presencia digital de la provincia argentina de Río Negro que trabajan en el diario Río Negro y en el diario Noticias de la Costa; periodistas de medios comunitarios con fuerte presencia en la red, y cuatro líderes de comunidades digitales en las redes sociales. Respecto de los medios comunitarios, la falta de estabilidad en la publicación y la imprevisibilidad de los flujos provocaron inconvenientes para realizar una selección comparable con los medios industriales. Ya en trabajos previos se había notado la intermitencia que presenta este tipo de emprendimientos periodísticos dentro de la provincia (Gorostegui, 2015, p. 13) y la volatilidad del mercado de publicaciones digitales que ello implica.

En este proyecto, se elaboraron correlaciones entre análisis de contenidos producidos por los profesionales que accedieron a las entrevistas entre los meses de marzo y junio del 2017, y las intervenciones en las redes de los informantes clave, elegidos por la cantidad de seguidores, así como por la incidencia de sus publicaciones dentro de sus comunidades y en trabajos periodísticos tradicionales, dentro del mismo lapso. De ese cruce, surgen algunas características que requieren ser corroboradas a partir de estudios cuantitativos que permitan saber si los posicionamientos de los informantes clave marcan tendencia dentro de las comunidades de usuarios o, como podría hipotetizarse, establecen liderazgos que tampoco permiten demasiada interacción.

Según datos de investigaciones realizadas por este mismo equipo de trabajo, los usuarios confían más en sus pares que en los periodistas, los políticos y la autoridad científica. De este modo, la negociación necesaria para no perder público (Luchessi y Cetkovich, 2007, p. 251) se ve desbalanceada hacia el lado de la audiencia y genera la necesidad de elaborar nuevos criterios para construir noticiabilidad. Si bien la atención no se centra en comunidades de adolescentes, los datos del estudio del Ente Nacional de Comunicación señalan que 9 de cada 10 de ellos se informan por las redes sociales, usan el primer enlace en las búsquedas y definen pobremente la confiabilidad de los sitios en los que suelen consultar (Ballarino, 2017). En términos de pensar una comunicación informativa hacia adelante, resulta indispensable profundizar en las estrategias para la optimización de los contenidos si se quiere competir con información de calidad.

En las primeras indagaciones, encontramos que el uso de reglas de SEO (Search Engine Optimization) se limita a los medios más profesionales $\mathrm{y}$, en el caso de las contribuciones comunitarias o de usuarios individuales, no aparecen huellas de las técnicas que lo sustentan. Para analizar la utilización 
de estas reglas, tomamos un corpus de materiales producidos por nuestros informantes clave y examinamos el contenido en cuanto a la aplicación de etiquetas, los títulos vinculados con los hechos que pudieran producirse y la estructura de las publicaciones. En este punto, si se siguen las preferencias de las audiencias de los medios digitales (Boczkowski y Michelstein, 2013) y se las compara con las publicaciones en las redes sociales, surge una pregunta insoslayable que reconfigura las rutinas de los periodistas y los análisis acerca de la industria informativa: ¿qué comprenden los productores y los consumidores por información?

Para dar cuenta de ello, se realizaron entrevistas en profundidad en relación con las variables más estables surgidas del primer análisis de contenidos. Las condiciones de trabajo y las relaciones con los usuarios fueron dos dimensiones consideradas a la hora de elaborar cuestionarios semiestructurados. Por investigaciones previas a la actual, sabemos que hace al menos veinte años que los avisos publicitarios, el material de entretenimiento, los deportes y secciones blandas son los contenidos preferidos por la audiencia de la prensa tradicional (Luchessi, 2006). Boczkowski y Michelstein (2013) agregan que estas preferencias son estables mientras no haya una necesidad imperiosa de información dura. Los casos que tienen en cuenta son los procesos electorales o las situaciones de crisis. Es en esos momentos cuando la brecha tiende a reducirse.
A partir del volumen de tópicos que circulan en las redes, se advierte que en ellas se mantiene cierta estabilidad. Para medirlo, utilizamos una matriz en la que buscamos los temas más estables. Una de las dimensiones, que luego fue desagregada por subtemas, fue el aporte de los usuarios a los contenidos de los medios para analizar las brechas de intereses entre productores profesionales y usuarios de plataformas en la red.

\section{Hallazgos}

Una de las constantes más estables que surgen del análisis de contenidos es que las rupturas de intereses entre productores y usuarios tienen un mayor impacto en lo que en los sistemas tradicionales se conocía como líderes de opinión. Si bien conservan su autoridad en aquellos sectores más informados y politizados, en términos de masividad su influencia es decreciente. En este sentido, los cortes etarios que se realizan en todos los estudios de consumo permiten ver que los jóvenes conocen mucho más a las estrellas de las redes que a dirigentes, periodistas, actores y personajes que circulan por la industria mediática tradicional.

Por su parte, aquello que antes 1lamábamos público constituye ahora comunidades activas, colaborativas, participativas y cuestionadoras (Luchessi, 2018). A su vez, se percibe una retroalimentación que, a fuerza de algoritmos y sugerencias de las plataformas para su interconexión, opera sobre la decisión de compartir información (Jenkins, Ford y 
Green, 2013), con su consecuente inserción de nuevos actores en el proceso de newsmaking. La escasa incidencia de Twitter entre las preferencias de los grupos mayoritarios y el uso compulsivo de esta red que se observa por parte de líderes tradicionales y sectores más politizados hacen prever que la repercusión de los debates, agendas y preocupaciones que circulan allí se torne cada vez más marginal en relación con las comunidades masivas de usuarios.

Con este panorama, un creciente interés por las secciones blandas hace que los medios negocien o desfallezcan. Del lado de las comunidades, las sugerencias de las redes, sustentadas en datos de navegación, flujos e intereses, conducen a la consolidación de universos donde no se expresan heterogeneidades y el pluralismo parece inviable. El impacto de esta conformación comunitaria homogénea redunda en la creación de mundos paralelos, irreconciliables, en los que los datos no parecen ser necesarios. Al mismo tiempo, y solo si coinciden las agendas, esas comunidades exigen de los formadores de opinión posicionamientos claros, que no dejen dudas, aunque no puedan sustentarse concretamente en información.

El fino equilibrio entre la satisfacción de unas comunidades que demandan definiciones antes que datos, celebraciones o condenas sin ningún punto medio, y la responsabilidad profesional de los productores informativos, que fluctúan entre el deber ser de la profesión y la viabilidad del negocio del que esperan subsistir, no encuentra en los hechos estrategias adecuadas para la producción. En un juego riesgoso, el periodismo entrega los tópicos a los usuarios a cambio de clics, navegaciones y posicionamientos. El sistema político, en tanto, participa de las plataformas como si fueran una pizarra de anuncios o una propagadora sin interacción.

De estas estrategias comunicacionales se desprenden dos fenómenos de impacto para la calidad democrática y la rutinización informativa. Por un lado, la sensación de acceder directamente a la fuente oficial (que puede estar mediada por la acción de profesionales de la comunicación política) y, por otro, la descalificación de todas las instituciones que ordenaron la vida social y democrática hasta el surgimiento de las redes. La horizontalidad que plantean las formas de relación reticular pluraliza las voces y cuestiona la autoridad. Los pares se vuelven confiables, el saber científico se relativiza, los liderazgos de opinión se erosionan y la democracia se cuestiona casi en su totalidad. A la vez, surgen problemas respecto de la información que circula, las fuentes que la producen, la intervención de quienes la gestionan y sus impactos en una opinión pública que prefiere argumentos para sostener sus propios posicionamientos, prejuicios y creencias antes que datos y elementos para construir su opinión.

Entonces, dentro de una matriz con nodos más o menos estables, las burbujas informacionales aportan insumos argumentativos, emotivos y aspiracionales. Las redes se consolidan en cruces de comunidades homogéneas, donde la idea 
de mayoría influyente se solventa en un circuito de satisfacción de la demanda, empatía sin dobleces e incapacidad de discusión. El fenómeno del bloqueo y la amenaza de la eliminación de amigos atraviesan la vida social online y offline. La ilusión de la última palabra. La de la clausura del debate. La de la incapacidad de la duda. La de la imposibilidad de contrastación. Así, las certezas impuestas en un abanico de creencias - que van desde la necesidad de "soltar" hasta la despedida de técnicos de fútbol o gabinetes de gobierno completos- no resisten ningún cuestionamiento que requiera argumentación. En esos casos, la incomodidad frente a lo heterogéneo impulsa a expulsar, a descartar, a restablecer el orden incuestionable. El desacuerdo se resuelve con violencia.

El poder, en este marco, no se erosiona por la presencia de plataformas. En tal caso, las mermas en la confianza, así como el descrédito de los liderazgos y la institucionalidad, se apoyan en un cambio cultural en el que las tecnologías digitales inciden en la vida cotidiana $y$, con sus nuevas formas, en la vida política e institucional. Los sistemas democráticos, que se regulan por leyes consensuadas en los parlamentos, entran en jaque cuando la desconfianza prima y las ideas conspirativas -aunque no logren formular argumentos sustentables- ponen en juego la lógica del bloqueo y la eliminación. En este sentido, la acción directa de los usuarios de las redes es central para la circulación de contenidos fuera de los medios tradicionales. Aun así, la idea de pertenencia comunitaria se institucionaliza cuando el material se replica en la industria tradicional.

Desde este punto de vista, la estabilidad en las formas de interacción constituye un aporte para pensar qué cambia respecto de los usuarios digitales comparados con las audiencias tradicionales. Y, además, de qué modo estas acciones hacen posible vislumbrar nuevas maneras en que los productores de información pueden relacionarse con sus usuarios.

La viralización, que parece sostener el interés de distintas comunidades de usuarios, termina por insertarse en los contenidos de la prensa tradicional en la medida en que la cuantificación instantánea del consumo, a partir del uso de herramientas analíticas, permite saber cuántos clics recibe cada contenido $\mathrm{y}$, a partir de esos datos, se decide la inclusión. Entonces, no importa cuándo, ni dónde, ni quién, sino solo la cantidad de clics y views avalan la popularidad de un contenido para ser tenido en cuenta como acontecimiento noticiable y garante de pulsos que mantengan el flujo del sitio. Miles de cibernautas comparten material de sus preferencias. Lo público se mezcla con lo privado, lo banal con lo esencial y el acontecimiento común con la noticia. Sin embargo, estas mezclas, que devienen preferencias, no son esencialmente temáticas. La réplica de contenidos se asocia a los posicionamientos que pueden medirse en relación con tendencias ideológicas, religiosas, sociales y culturales. 
No obstante, en núcleos duros más politizados, la agenda política, que en muchos casos surge de las intervenciones de los representantes del Estado y sus adversarios en la oposición, admite intervenciones que se asemejan más a las que podrían tener lugar en los locales partidarios que a las que se realizan cuando son los usuarios los que generan tópicos y empujan las pautas de publicación.

Lo novedoso radica en la constitución de nodos, mayoritariamente opuestos, donde las posiciones excluyen de plano a todas las que no se les parecen, independientemente de la veracidad, el profesionalismo y el rigor productivo con el que las piezas informacionales se hayan puesto a circular. Sin embargo, y a pesar de tener posicionamientos poco plurales y en algunos casos hasta relacionados con la censura, varios de los usuarios entrevistados refieren que el bloqueo y la eliminación son prácticas corrientes. En todos los casos, se presentan publicaciones donde ese otro censurado no es objeto de indiferencia, sino, más bien, de descalificación.

También resulta interesante advertir que, para los usuarios, la precisión informativa no es motivo de preocupación. Para ellos, lo verdaderamente relevante de las intervenciones públicas de las voces institucionalizadas es la explicitación de las posiciones (centradas en un dispositivo a favor o en contra) que les permita situarlos dentro o fuera de su propia comunidad. No importa si agregan información o demuestran inadecuación en el tratamiento profesional. La exhortación, entonces, es de identificación o repudio sobre cuestiones puntuales.

Según Rincón (2013), el papel del periodismo en plataformas digitales irá virando a tareas parecidas a las que realizan los DJ. Cortar, enlazar, mezclar. Del mismo modo, advertimos que algunos usuarios hacen las mismas actividades y, tanto unos como otros, se arrogan ocurrencias, chistes, reflexiones producidas por miembros de sus redes, pero que no alcanzan notoriedades como para ocupar lugares de influencia virtual. Respecto de los profesionales, todos coinciden en que, ante la imposibilidad de recurrir a coberturas en tiempo real, el editing prevalece sobre el resto de las instancias del newsmaking. La selección y la jerarquización surgen de algoritmos expresados en las métricas que expresan las navegaciones de los usuarios. De este modo, lo que se impone es una satisfacción de la demanda cada vez más alejada de la idea de calidad informacional.

También pudimos observar que, si bien hay un buen trabajo realizado sobre la gestión de los flujos noticiables, el concepto de pulso suele gestionarse de mejor manera entre los usuarios más avezados que circulan por la red. En este sentido, son notorios los reflejos con los que los profesionales empujan contenidos virales hacia sus propias pautas para sostener el tráfico y la circulación. Puestos a analizar los criterios selectivos, la viralización se vuelve fundamental a la hora de tomar decisiones en la edición. 


\section{Conclusión}

A la idea unidireccional de la información tradicional se contrapone una red cuyos nodos no siempre son profesionales, sino que se constituyen por la popularidad que puedan alcanzar. Así, mientras las redes rebasan de imágenes, gifs y microvideos, la carga textual de muchas de las noticias que se publican en los sitios informativos va contra la corriente de cualquier narrativa transmedia.

En el equilibrio entre la satisfacción de la demanda, la acción de los usuarios y la desconfianza institucional es donde los contenidos informativos mutan y se alejan de lo que no hace tanto fueron valores noticiosos. Las reglas productivas, pero también las de convivencia social, quedan entre paréntesis en las expresiones digitales. Es objeto de próximos trabajos analizar la consistencia de estos rastros en la producción de sentido social. En tanto, la imagen fija permite establecer correlaciones estructurales entre la vida online y offline, disrupciones acerca de los temas y confusiones sobre el ejercicio del periodismo y la vida democrática.

\section{Referencias}

Aguado, J. (2013). La industria del contenido en la era Post-PC. Horizontes, amenazas y oportunidades. En J. Canavilhas (Org.), Noticias e mobilidade o jornalismo, na era dos dispositivos moveis (pp. 5-32). Covilhã: Livros Labcom.

Amado, A. (2016a). Del newsroom al cloudsroom. El periodista y los productores de información. En L. Luchessi y L. Videla (Comps.), Desafíos del periodismo en la sociedad del conocimiento (pp. 11-18). Viedma: Editorial Universidad Nacional del Río Negro.

Amado, A. (2016b). Periodismos argentinos. Modelos y tensiones del siglo xxı. Buenos Aires: Infociudadana; Konrad-Adenauer-Stiftung.

Ballarino, F. (1 de septiembre del 2017). Ocho de cada diez chicos se quedan con la primera página que ven en la web. Perfil. Recuperado de http://www.perfil.com/ciencia/ocho-de-cada-diez-chicos-se-quedan-con-la-primera-paginaque-ven-en-la-web.phtml

Barnes, J. A. (1954). Class and Committees in a Norwegian Island Parish. Human Relations 7, 39-58.

Boczkowski, P., y Michelstein, E. (2013). The News Gap. When the Information Preferences of the Media and the Public Diverge. Londres: MIT Press.

Boczkowski, P., Michelstein, E., y Matassi, M. (29 de junio del 2016). El medio ya no es el mensaje. Revista Anfibia. Recuperado de http://www.revistaanfibia.com/ 
ensayo/medio-ya-no-mensaje/http://www.revistaanfibia.com/ensayo/medioya-no-mensaje/

Bott, E. (1957). Family and Social Network. Londres: Tavistock.

Cabot, D. (16 de agosto del 2015). Un celular y medio por cada argentino. La Nación. Recuperado de https://www.lanacion.com.ar/1819478-un-celular-y-medio-porcada-argentino

Calvo, E. (2015). Anatomía política de Twitter en Argentina. Tuiteando \#Nisman. Buenos Aires: Capital Intelectual.

Canavilhas, J. (2009). Ensino do jornalismo: o digital como oportunidade. En J. Fidalgo y S. Marinho (Org.), Actas do Seminário JORNALISMO: Mudanças na Profissão, Mudanças na Formação (pp. 49-56). Braga: Universidade do Minho, Centro de Estudos de Comunicação e Sociedade (CECS).

Ente Nacional de Comunicaciones (Enacom). (2017). Penetración nacional de la telefonía móvil (accesos por cada 100 habitantes). Recuperado de http://datosabiertos. enacom.gob.ar/dataviews/241158/penetracion-nacional-de-la-telefonia-movilaccesos-por-cada-100-habitantes/

Ford, A. (1994). Navegaciones. Comunicación, cultura y crisis. Buenos Aires: Amorrortu.

Gans, H. (1979). Deciding What's News. A Study of CBS Evening News, NBC Nightly News, Newsweek, and Time. Nueva York, NY: Random House.

García, J. (19 de junio del 2017). Las empresas periodísticas no pueden depender de la publicidad. El País. Recuperado de https://retina.elpais.com/retina/2017/06/16/ tendencias/1497627403_854593.html?id_externo_rsoc=TW_CC

García, L. (2008). Distribución y promoción del producto informativo. En G. Aguado et al., Organización y gestión de la empresa informativa (pp. 129-141). Madrid: Síntesis.

García Canclini, N. (1990). Culturas híbridas. Estrategias para entrar y salir de la modernidad. México D. F.: Grijalbo.

Gitlin, T. (2005). Enfermos de información: de cómo el torrente mediático está saturando nuestras vidas. Barcelona: Paidós.

Gómez, R. M., Ortiz, M., y Concepción, L. E. (2011). Tecnologías de la comunicación y política 2.0. Espacios Públicos, 14(30), 72-84.

Gorostegui, C. (2015). Los medios digitales y la inmigración, una cuestión de agendas (tesina de grado). Viedma: Universidad Nacional de Río Negro.

Habermas, J. (1981). Historia y crítica de la opinión pública. Barcelona: Gustavo Gili.

Igarza, R. (2009). Burbujas de ocio. Nuevas formas de consumo cultural. Buenos Aires: La Crujía. 
Jenkins, H. (2008). Convergence Culture. La cultura de la convergencia de los medios de comunicación. Barcelona: Paidós.

Jenkins, H., Ford, S., y Green, J. (2013). Spreadable Media: Creating Value and Meaning in a Networked Culture. Nueva York, NY: New York University Press.

Landi, O. (1992). Devórame otra vez. Qué hizo la televisión con la gente. Qué hace la gente con la televisión. Buenos Aires: Planeta.

Lippmann, W. (1922). Public Opinion. Nueva York, NY: The Free Press.

Luchessi, L. (2006) Informe final del Seminario de Política y Medios. Buenos Aires: Universidad de Buenos Aires.

Luchessi, L. (2013). Calidad informativa. Escenarios de poscrisis. Buenos Aires: La Crujía.

Luchessi, L. (2016). Descentramientos, influencias y reacomodamientos en el ejercicio periodístico. En A. Amado (Ed.), Periodismos argentinos. Modelos y tensiones del siglo XXI (pp. 37-49). Buenos Aires: Infociudadana; Konrad-Adenauer-Stiftung.

Luchessi, L. (2018). Viral News Content, Instantaneity, and Newsworthiness Criteria. En R. Rampazzo Gambarato y G. Alzamora (Eds.), Exploring Transmedia Journalism in the Digital Age (pp. 31-48). Hershey, PA: IGI Global.

Luchessi, L., y Cetkovich, G. (2007). Punto ciego. En L. Luchessi y M. Rodríguez (Coords.), Fronteras globales. Cultura, política y medios de comunicación (pp. 251273). Buenos Aires: La Crujía.

Martín-Barbero, J. (1987). De los medios a las mediaciones. Comunicación, cultura y hegemonía. México D. F.: Gustavo Gili.

Martini, S. (2000). Periodismo, noticia y noticiabilidad. Bogotá: Norma.

McCombs, M. (2004). Setting the Agenda. Cambridge: Polity Press.

McLuhan, M. (1964). Understanding Media. The Extensions of Man. Cambridge, MA: The MIT Press.

Newman, N. (2017). Executive Summary and Key Findings. En N. Newman, R. Fletcher, A. Kalogeropoulus, D. A. L. Levy, y R. K. Nielsen (Eds.), Reuters Institute Digital News Report 2017 (pp. 12-13). Recuperado de https://reutersinstitute.politics.ox.ac.uk/sites/default/files/Digital\%20News\%20Report\%20 2017\%20web_0.pdf

Piqué, A. M. (2008). Introducción. En R. Salaverría y S. Negredo, Periodismo integrado. Convergencia de medios y reorganización de redacciones (pp. 7-12). Barcelona: Editorial Sol.

Pozzo, E. (2015). Edición periodística online. La transformación de los criterios del papel a la web (tesis de maestría). Buenos Aires: Universidad de San Andrés. 
Price, V. (1994). La opinión pública. Esfera pública y comunicación. Barcelona: Paidós.

Rincón, O. (2013). El periodista DJ es el medio. En L. Luchessi (Comp.), Calidad informativa. Escenarios de poscrisis (pp. 9-31). Buenos Aires: La Crujía.

Rost, A. (2017). Argentina. En N. Newman, R. Fletcher, A. Kalogeropoulus, D. A. L. Levy, y R. K. Nielsen (Eds.), Reuters Institute Digital News Report 2017 (pp. 104107). Recuperado de https://reutersinstitute.politics.ox.ac.uk/sites/default/files/ Digital\%20News\%20Report\%202017\%20web_0.pdf

Scolari, C. (2008). Hipermediaciones. Elementos para una teoría de la comunicación digital interactiva. Barcelona: Gedisa.

Scolari, C. (27 de junio del 2013). Spreadable Media: entre la cultura de masas y la colaborativa (II) [mensaje en un blog]. Recuperado de https://hipermediaciones. com/2013/06/27/spreadable-media-entre-la-cultura-de-masas-y-lacolaborativa-ii/

Sibilia, P. (2012). La intimidad como espectáculo. Buenos Aires: Fondo de Cultura Económica.

Tuchman, G. (1978). Making News. A Study in the Construction of Reality. Nueva York, NY: The Free Press.

Wasserman, S., y Faust, K. (1994). Social Network Analysis: Methods and Applications (vol. 8). Cambridge: Cambridge University Press. 